\title{
THE IMPLICATIONS OF E-SOCIETY IN THE BUYING PROCESS OF AN UNIVERSITY PRODUCT: A TIME SERIES ANALYSIS
}

\author{
Ion-Dănuț LIXANDRU \\ Bucharest University of Economic Studies, Romania \\ danut.lixandru@gmail.com
}

\begin{abstract}
In the current situation of universities, a moment of searching for the best practices of attracting students, for the best ways of networking and interconnecting, predicting and knowing the changes features over time on student decision, is a big step ahead of competition which becoming fiercer. The use of time series analysis is a relatively new paradigm and little or not exploited by the academic environment in Romania, but is a good technique to observe the differences between generations of students. Using this analysis, as well as the best marketing techniques, in this case university marketing, can represent the key to providing satisfaction in the best conditions and further development of society. The socio-economic dynamism of the university education sector, which is extremely important in the economy of a country, makes it necessary to address the changes brought about by the new society. This series of economic, social, political and administrative changes, with a major impact on people and not only, are produced over time and modifying psychological characteristics and causing differences of conception from one generation to the next, and, of course, affect the way they take a buying decision. This article aims to find a correlation between the development of the $e$-society and the choice of a university product, in this case a bachelor program, and his implication on the psychology of the new generation of student.
\end{abstract}

Keywords: e-society, marketing, university marketing, time series analysis

JEL Classification: M31, I21, B55

DOI: $10.12948 / \mathrm{ie} 2019.04 .07$

\section{Changes produced by the e-society}

In the new circumstances of today's society, the need for continuous adaptation, as well as the prediction of consumer wishes, become a sine-qua non element in any type of organization. Changes in contemporary society bring about needs or desires different from those of individuals of past generations. Observationally, one can distinguish the idea that the current information-based society, also called the e-society, is much easier to carry out the exchange function between customers and organization (B2C) or even between organizations (B2B). The diversity of the economic processes carried out in the new economy leads to a change in the economic, social and political environment and puts the organization's relationship with the client as the foundation for good functioning.

A content of genuine relevance is Alnfrah and Mouselli [1] statement, who claim that we live in the age of "globalized knowledge that has become the basis of the production process" and more than ever, this process is not composed from physical elements but from individuals and social capital, which represent the most valuable resource of organizations. So, from the moment when the emphasis was on holding the private monopoly and the waste of material goods (the capitalist and industrial society), it is at a time when the intangible (information) possesses the total attention. 
Along with this development, the trigger factor, namely the Internet, has become the main environment in which organizations carry out their activities, and at the same time has changed the way buying decisions are made.

At the beginning of e-commerce (1990s), the period was a search and experiment, in the 2000s the strategy was a reassessment, and between 2002-2008 e-commerce grew more than 25\% [2], nowadays one of the most used networks that make it possible to grow has managed to bring $33 \%$ of the world's population to the same space [3].

The role of marketing science in today's society becomes essential to link the organization to its consumers. Thus, marketing in the e-society puts in its center the individualized client, with his needs and desires, trying to fulfill as many of them as possible. For a permanent adaptation to environmental requirements, both marketing and the e-society requires a forward-looking approach to climate change in their own habitat. Social and economic dynamism forms a bridge between these two distinct domains that lead to a new form of economy.

The wide-ranging nature of the e-society allows it to transpose and apply it in different environments, such as political, administrative, social, legal, economic, cultural and individual [4]. It is noteworthy, in this case, at the individual level, in the behavioral sense, the changes brought by the e-society, which, according to Andreas [5], brings new expectations even in terms of the working environment, "the esteem and the opportunity to leave a mark" become important elements for the employees.

The development of this society therefore covers a multitude of areas, which provide them with various means of stabilization, modernization or even growth / evolution. A simple overview (over a long period of time) over an area where the e-society has its footprint can confirm the gradual transition to a higher level.

By accepting the new dimension of the economy [6], emphasis is placed on the importance of higher education in the new society as a branch which makes an important contribution to expanding the knowledge capacity, increasing the quality of the workforce, innovation and competitiveness.

If most theories are based on explanations of changes made by specific activities, the global process at individual (psychological) level is less targeted. As Stoica says, the individual receives a number of advantages with much easier access to information and the possibility of "social interaction" [4], but the current trend shows an increase in the lack of physical interaction between idioms. Thus, the decisions they make, are not an impulse of desire, but an external influence on the part of society created in the virtual environment, the imposition of conformist norms, and therefore it acts upon the individual as a stimulus with an expected response, similar to the principle training.

What the current society proposes is the continuous development with the help of the Internet, a single network that has managed to bring to the same environment the majority of the individuals of the society and which provides the advantage of fast information that can be processed and adapted without interruption, each node (person) adding value to the. The users of these networks are looking for (and the internet network offer) social interaction, free facilities, control and / or refresh of knowledge, all created by the desire to know and involve of members [7]. However, these desires create groups with different behaviors and, on the same principle, differences between age generations of users, and also, as expected (in case of university), this transformation has repercussions both at the level of the employees of the universities as well as in the case of the employers' requirements, the beneficiaries of the new labor force, which in turn imposes new rules and training needs. Good functioning of this chain brings satisfaction to the consumers of universities, profitability for them as well as for employers and a positive benefit for the society. 
The tendency and influence exerted, by this society, on the individual can be seen from the differences and characteristics of the generations. If, for example, we turn our attention to the last three generations, i.e. the x generation (born between 1965-1979), the generation y / millennials (born between 1980-1996) and the $\mathrm{z}$ generation (born after 1996), the discrepancy is quite great. In the case of the x-generation, information was hard to find, and the technology process only exists at industrial level, millennials are the so-called "pioneers" of digitization, and as many authors argue in the article written by Nicholas and Wright [8], they have grown in the era of digitization and are connected through social media, and their way of information is based on extensive use of technology. The generation replacing the millennials, suffers a total behavioral change. Compared to both of these generations, they were born in a technology world. Differences between millennials and centennials can be seen in the following figure (Figure 1).
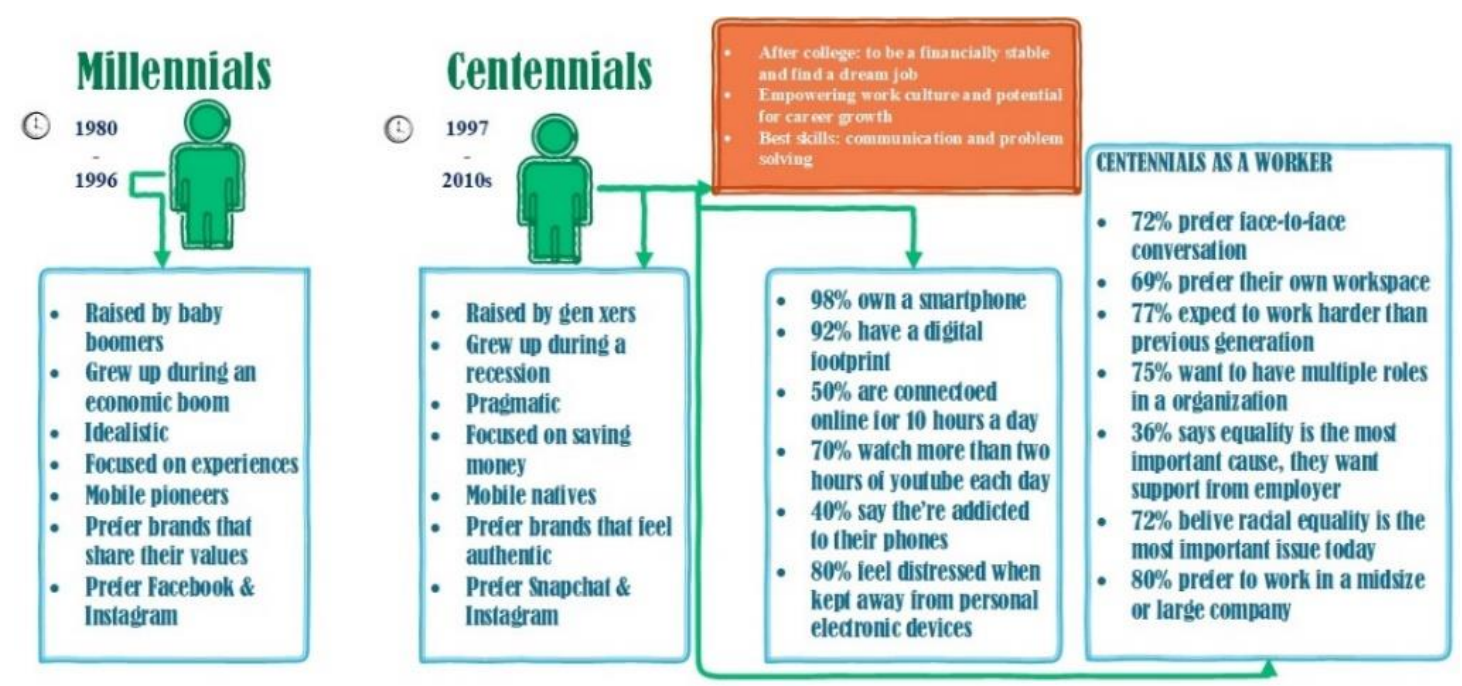

Figure 1. Differences between y generation and z generation Source: Adapted after Desjarinds, J (2019) [9]

In order to understand the differences caused by the e-society effect, I have investigated their decisional differences, in the context of the influence of the e-society, starting from the prerequisites developed by the science of attracting consumers, namely marketing, in an area where the decision is taken in the long term and looks at the future of these generations, education.

Zaiţ [10] asserts that educational marketing aims at issuing, amplifying and accommodating study programs in relation to market requirements, as well as applying communication and motivation techniques, more specifically knowledge of consumers and adaptation to the new conditions created by society. So the implications of the new e-society for this area make it possible to find a way to develop, considering the changes it produces.

Following the article, we will see if the differences imposed by the e-society reach the purchasing decision rule by analyzing a series of time.

\section{The research methodology}

The basis for defining the purpose of the research is the determination by forecast of the number of students admitted to the Faculty of Marketing from ASE Bucharest, considering as a factor of influence on the decision to choose the university program, the e-society and the changes offered to this field of study on consumer behavior. 
The aim of the research is to determine the most appropriate model of forecasting and to know the extent to which the e-society has, over a period of time, been a factor of growing influence over the decision to acquire a university program.

At the level of objectives, research aims at:

- Determining the extent to which changes made by the e-society have been considering when enrolling in college and reporting differences between generations;

- Determining the evolution of the number of students;

- Identifying the best predictive method, related to the studied subject;

- Measuring the degree of association of the number of students admitted to the Faculty of Marketing with those successful at the Baccalaureate exam for a period of 10 years.

Research assumptions:

- H1. Generation z (centennials) took a great considering of technological changes when purchasing the university product (license program);

- H2. Most respondents belong to the generation with the lowest number of admitted in the analyzed time series;

- H3. The number of students admitted to the Marketing Faculty is directly proportional to the number of students admitted to the Baccalaureate exam;

- H4. The tendency of the admitted is an ascending one,

- H5. The best way to predict is to use the linear model;

- H6. Generation differences determine the volatility of the number of admitted students.

I have collected the secondary data from the Faculty of Marketing (ASE Bucharest), namely the number of students admitted here, starting with the 2009-2010 promotion so far, was organized in order to carry out the research as objectively as possible. Another source of data was a short survey that was started using the Google Forms platform, containing a questionnaire with 3 questions, which I have shared with the official faculty group Facebook network, with time coordinates 17-24 February 2019.

All observation units were able to complete the questionnaire, the sampling method being an exhaustive one.

I analyzed the date using SPSS and Microsoft Excel.

The following mathematical equations which I used to determine the prediction model and the residual error size as well as the average absolute deviation:

The linear model: $Y_{i}=a+b * X_{i}$

The polynomial model: $\mathrm{Y}_{\mathrm{i}}=\mathrm{a}+\mathrm{b} \times \mathrm{X}_{\mathrm{i}}+\mathrm{c}^{*} \mathrm{X}_{\mathrm{i}}^{2}$

The exponential model: $\mathrm{Yi}=\mathrm{a} \times \mathrm{b}^{\mathrm{Xi}}$,

Where: $\mathrm{Yi}$ - the value of the predicted variable in the "i" period;

$\mathrm{Xi}$ - reference period "i";

$\mathrm{a}, \mathrm{b}$ - model parameters

Residual Error: $\mathrm{SS}_{\mathrm{E}}=\sum_{i=1}^{n}\left(y_{i}-\hat{y}_{i}\right)^{2}=\sum_{i=1}^{n} e_{i}^{2}$

Average absolute deviation: $\mathrm{AMA}=\frac{\sum_{i=1}^{n}\left|y_{i}-\hat{y}_{i}\right|}{n}$

\section{Research results}

After the questionnaire was administered, a total of 54 respondents responded as presented in Figure 2.

The hypothesis from which this study has been started, states that generation $\mathrm{Z}$ takes very much into consideration technological change when deciding to choose a university product, as can be seen (fig.2) from 2015 onwards, 2016, when they were admitted, 40\% of them say they have 
taken the technological dynamics to a very high degree, followed by those with no less than $25 \%$, then those with very little $20 \%$ and $15 \%$ to a large extent, by consequently $\mathrm{H} 1$ can be accepted.

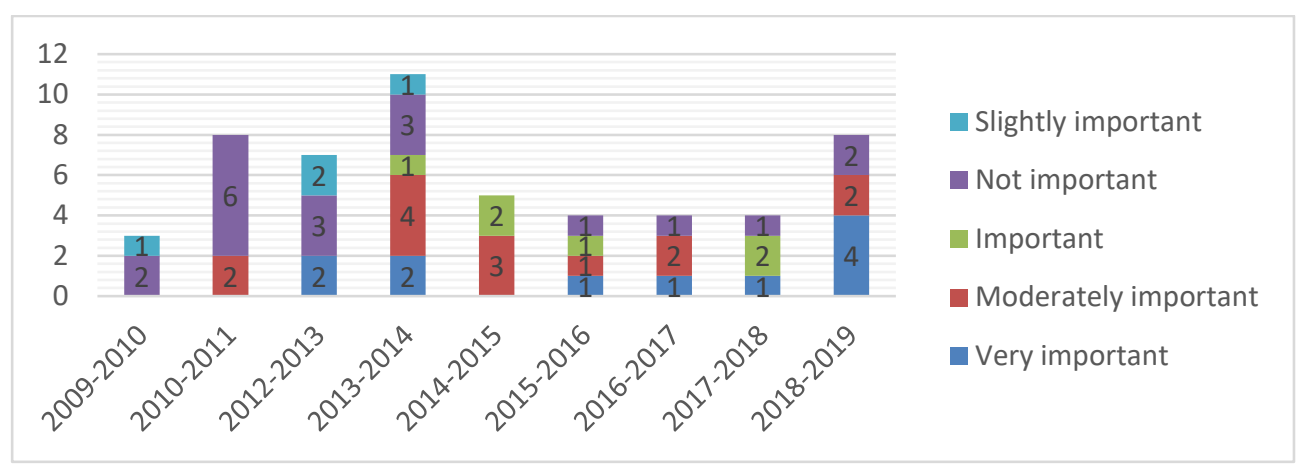

Figure 2. Distribution of responses

As can be seen in Table 1, contrary to the H2, 2010, 2013 and 2014 have the largest number of representatives, and the majority (37.5\%) said that the evolution of technology has influenced very little in the choice of the faculty, therefore, we can assert the null hypothesis.

Table 1. Number of student admitted to Faculty of Marketing

\begin{tabular}{|c|c|}
\hline Year & Admitted to college \\
\hline 2009 & 455 \\
\hline 2010 & 353 \\
\hline 2011 & 411 \\
\hline 2012 & 414 \\
\hline 2013 & 374 \\
\hline 2014 & 371 \\
\hline 2015 & 430 \\
\hline 2016 & 410 \\
\hline 2017 & 441 \\
\hline 2018 & 435 \\
\hline
\end{tabular}

In a logical order, the number of students should increase relative to the number of students who have obtained the Baccalaureate [11], but as can be seen in Figure 3, the fluctuations are slightly different, so the two values have the same proportional direction. Analyzing the link between the two variables, the Pearson correlation coefficient with the value of 0.084 shows a positive and directly proportional relationship, but with a very weak statistically significant relationship $(\mathrm{p}$-value $=0.817$ from Table 2$)$.

Table 2. Pearson Correlation

\begin{tabular}{|cc|c|c|}
\hline & & College & Baccalaureate \\
\hline \multirow{3}{*}{ College } & Pearson Correlation & 1 & .084 \\
& Sig. (2-tailed) & & .817 \\
& $\mathrm{~N}$ & 10 & 10 \\
\hline \multirow{3}{*}{ Baccalaureate } & Pearson Correlation & .084 & 1 \\
& Sig. (2-tailed) & .817 & \\
& $\mathrm{~N}$ & 10 & 10 \\
\hline
\end{tabular}




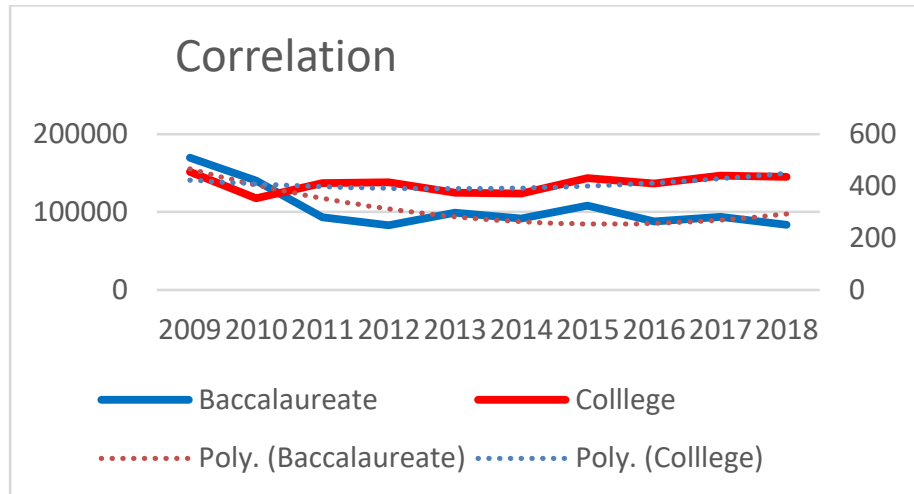

Figure 3. Graphical correlation of the number of students admitted to the successful baccalaureate

In order to calculate the trend of the chronological analysis, I determined, using the abovementioned mathematical equations, the equation applied for 3 different prediction models, the linear model, the polynomial model and the exponential model. As can be seen in the following graph, the differences between these models express an uncertainty about determining an ascending or descending trend, the linear and exponential models showing an increase and the polynomial showing volatility. The determination coefficient $\mathrm{R}^{2}$ calculated for each model shows very low values for the linear model (0.068) and exponential (0.0752), so we can see (in Figure 4) that both equations have a low degree of applicability of the regression equation and thus can be accepted the hypothesis according to which the trend is ascending, accepting the polynomial model equation.

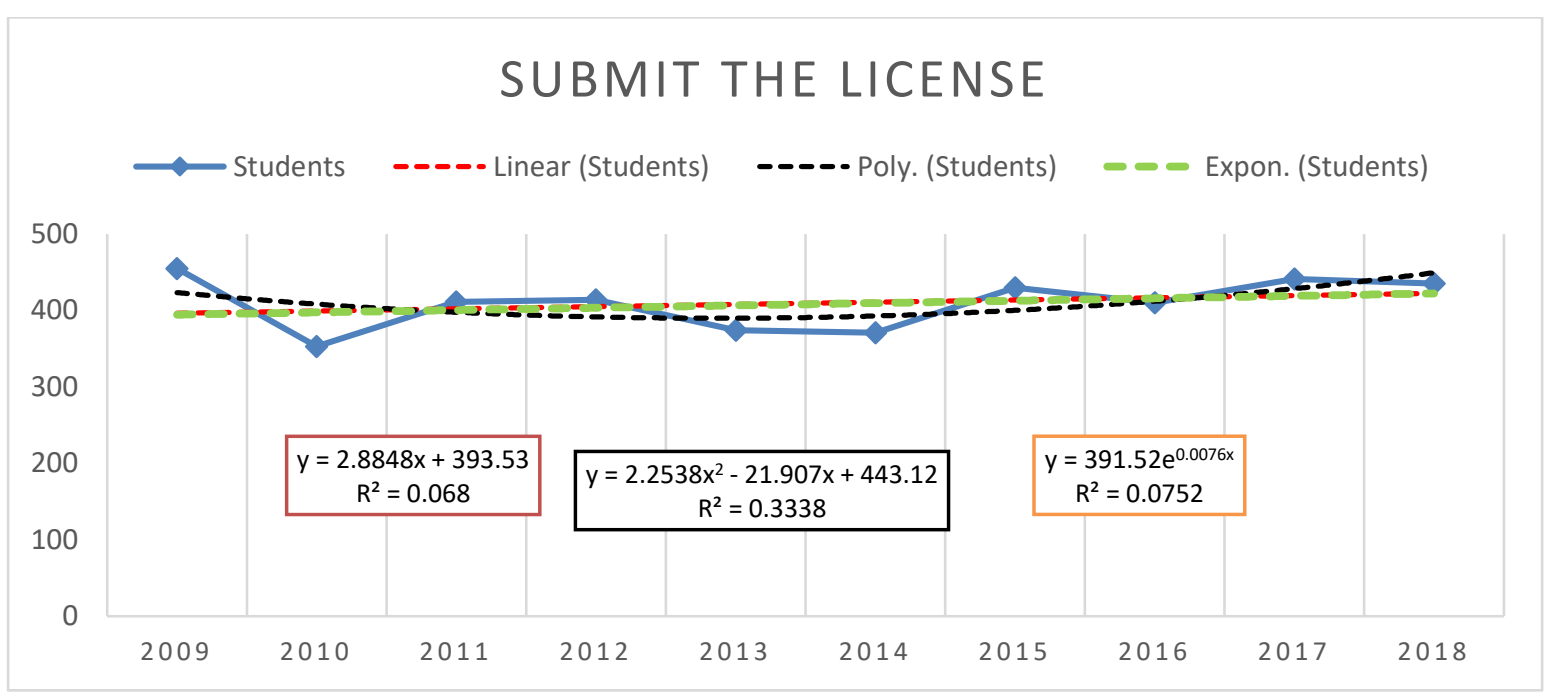

Figure 4. The trend of the registration number at the Faculty of Marketing

To determine with greater precision which of the models is best for estimating the number of students for the following years, the size of the residual error and the absolute mean deviation were calculated for all three models, as can be seen in Figure 5. 
www.conferenceie.ase.ro

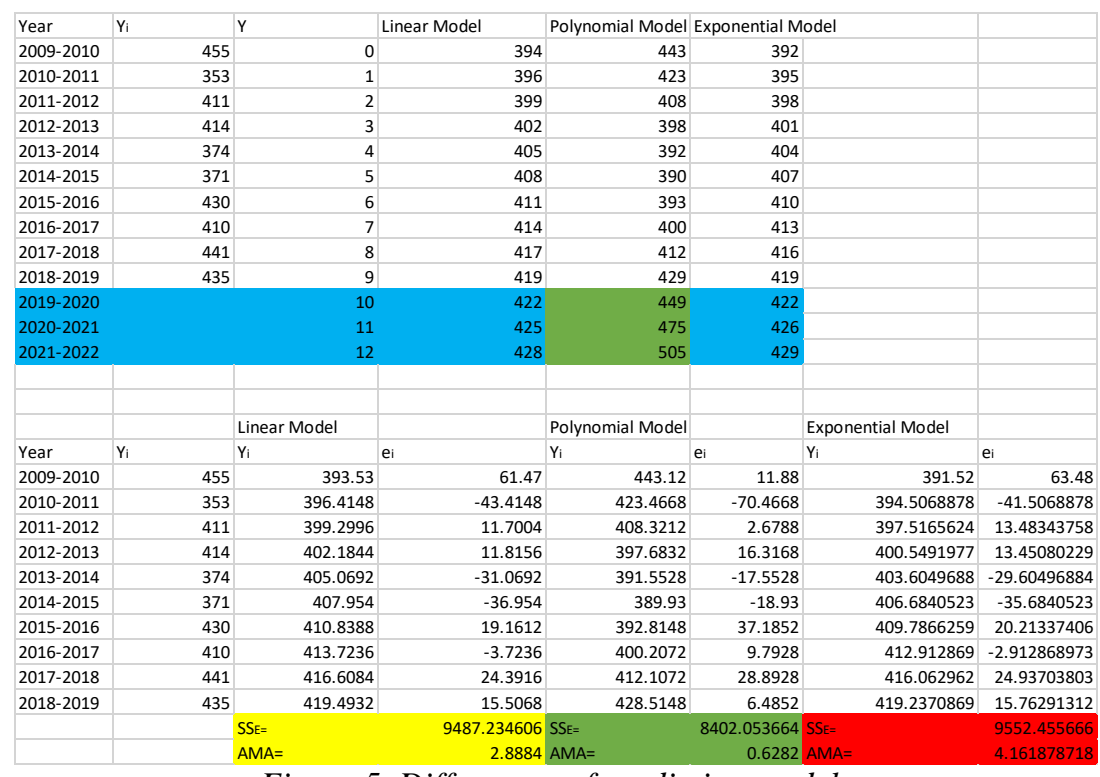

Figure 5. Differences of prediction models

According to the calculations, the best predictive model, with a residual dimension of 8402.05 and an absolute mean deviation of 0.628 , the most appropriate and closest to 0 values, is the polynomial model with the equation: $y=2.2538 \times 2-21.907 x+443.12$. Therefore, in line with the model's expectations, the most probable values for the following years are: 449, 475 and 505 students admitted to the Marketing Faculty, and we can reject the hypothesis that the most appropriate prediction model is the linear one.

Observationally, considering the previous analysis, I can argued that the fluctuation in the number of university admissions and the successful ones in the Baccalaureate exam is influenced to a large extent by the changes made by the e-society and the difference between generations presents the psychological consequences of the e-society. Therefore, the hypothesis that the volatility of the number of students is determined by changes in generations is confirmed.

\section{Conclusion}

To conclude what has been developed and demonstrated earlier, we can summarize the idea that today's society suffers a lot of changes due to the evolution of information and communication technology, both at the individual and at the organizational level. The new generation of individuals born with these tools at hand has a different conception of the choices they have to make, and the extent to which the technology / digital environment influences them increases as it offers them more benefits.

All these changes put the customer on the forefront and, practically, concentrating organizations' efforts on these developments and optimizations and on the marketing process offer both parties, and not only, long-term benefits, while at the same time bringing to the benefit of society a series of favorable results for the purpose of evolution.

The choice of the university, the place that gives them a broader perspective on their future, a vision and an opportunity for getting a job, with a special implication in the life of the new generation, is thus attained by the dynamics of the current society, and in the present case, university marketing, remains to develop new techniques for attracting students based on its exertions.

The more organizations or universities manage to keep up with the new technologies and the information is delivered more efficiently, the more likely it is to attract and / or maintain 
www.conferenceie.ase.ro

consumers, and their decision to choose a product / service becomes more anticipative and easy to be satisfied.

Although the most powerful organizations have moved into the online environment to be as close to their customers as possible, an effective marketing strategy includes various techniques or actions in the traditional environment but considering, into a large extent, changes made by the new society to the consumer.

Summarizing the aforementioned aspects, we can see that the key factor of the new society is the behavior of individuals or their modification, and its control offers an advantage to any organization, even universities that are responsible for the behavior of future generations.

\section{References}

[1] I. Alnfrah, S. Mouselli, "The Knowledge Society Vis-à-vis the Knowledge Economy and their Potential Development Impacts in Russsia," Journal of the Knowledge Economy, vol. 10, no. 1, 2019, pp. 205-220. [Online] Available at: https://link.springer.com/article/10.1007\%2Fs 13132-017-0448-2

[2] K. C. Laudon, C. G. Traver, "E-commerce business, technology, society," 10th eds., Pearson, 2014.

[3] Statista.com, 2019. Statista.com. [Online] Available at: https://www.statista.com/statistics/264810/number-of-monthly-active-facebook-usersworldwide/ [Accessed 2 March 2019].

[4] M. Stoica, "Premise ale trecerii la societatea informațională," Informatică Economică, vol. 16, no. 4, 2000, pp. 42-46, [Online] Available at: http://revistaie.ase.ro/content/16/stoica.pdf

[5] M. Andreas, "eDemocracy \& eGovernment - Stages of a Democratic Knoledge Society," 1st ed., Fribourg: Springer, 2012.

[6] L. Tetrovova, V. Vlckova, "The role of inter-university cooperation in the knowledge society." Perspectives: Policy and Practice in Higher Education, vol. 22, 2018, pp. 1-7. [Online] Available

at: https://www.tandfonline.com/doi/full/10.1080/13603108.2018.1519491

[7] M. Lucas, J. Ribeiro, A. Moreira, "Bypassing School Disenchantment: Strategies to Promote School Attainment," In: Information Systems, E-learning, and Knowledge Management Research: 4th World Summit on the Knowledge Society, WSKS 2011, Mykonos, Greece, September 21-23, 2011, revised selected papers. s. 1.: Springer-Verlag Berlin Heidelberg, 2013, pp. 1-6.

[8] T. Nicholas, M. Wright, "Generational differences: understanding and exploring generation z," Southwest Academy of Management Proceedings, 2018, pp. 177-185. Albuquerque. [Online] Available at: http://www.swamfbd.org/uploads/Proceedings_2018.pdf\#page=177

[9] J. Desjarinds, "Meet Generation Z: The Newest Member to the Workforce," 2019, February 14, [Accessed: February 25, 2019], Available at: https://www.visualcapitalist.com/meet-generation-z-the-newest-member-to-theworkforce/?fbclid=IwAR0E8oGfVDJpZEaYHEDEl7be_Azsv0uos8qhH85vMlA5rS9K_afFqOcjck

[10] A. Zaiț, "Marketingul Serviciilor,” Iași: Sedcom Libris, 2004.

[11] edu.ro. (2017, February 15). Bacalaureat 2017. [Online] Available at: https://www.edu.ro/sites/default/files/170710\%20BAC\%20DOSAR\%20v2.pdf 